\title{
Simultaneous Determination of Cortisol and Cortisone from Human Serum by Liquid Chromatography-Tandem Mass Spectrometry
}

\author{
Sanghoo Lee, ${ }^{1}$ Hwan-Sub Lim, ${ }^{2}$ Hye-Jin Shin, ${ }^{1}$ Seol-A Kim, ${ }^{1}$ \\ Jimyeong Park, ${ }^{1}$ Hyun-Chul Kim, ${ }^{1}$ Hyogyeong Kim, ${ }^{1}$ Hyung Joo Kim, \\ Yun-Tae Kim, ${ }^{1}$ Kyoung-Ryul Lee, ${ }^{1}$ and Young-Jin Kim ${ }^{1}$ \\ ${ }^{1}$ Department of Bioanalysis, Seoul Medical Science Institute \& Seoul Clinical Laboratories, Seoul 152-766, Republic of Korea \\ ${ }^{2}$ Department of Laboratory Medicine, Kwandong University College of Medicine, Gangneung 210-701, Republic of Korea \\ ${ }^{3}$ Department of Biological Engineering, College of Engineering, Konkuk University, Seoul 143-701, Republic of Korea
}

Correspondence should be addressed to Young-Jin Kim; yjkim@scllab.co.kr

Received 16 December 2013; Revised 5 February 2014; Accepted 5 February 2014; Published 6 March 2014

Academic Editor: Josep Esteve-Romero

Copyright (C) 2014 Sanghoo Lee et al. This is an open access article distributed under the Creative Commons Attribution License, which permits unrestricted use, distribution, and reproduction in any medium, provided the original work is properly cited.

A fast, sensitive, and selective liquid chromatography-tandem mass spectrometry (LC-MS/MS) method was validated and then the levels of cortisol and cortisone from sera of healthy adults were determined by the LC-MS/MS method. One hundred $\mu \mathrm{L}$ of serum sample was directly extracted by adding $2 \mathrm{~mL}$ ethyl acetate, followed by chromatographic separation on a C18 column with a mobile phase consisting of $5 \mathrm{mM}$ ammonium acetate and methanol $(25: 75, \mathrm{v} / \mathrm{v})$. The precision, accuracy, and average recovery of the method were $1.5-5.3 \%, 95.4-102.5 \%$, and $96.4 \%$ for cortisol, and $1.9-6.0 \%, 89.2-98.8 \%$, and $79.9 \%$ for cortisone, respectively. The method was linear from 1.0 to $500.0 \mathrm{ng} / \mathrm{mL}\left(r^{2}=0.999\right)$ for cortisol and 2.5 to $100.0 \mathrm{ng} / \mathrm{mL}\left(r^{2}=0.998\right)$ for cortisone. The limits of detection (LOD) and quantification (LOQ) were 0.2 and $1.0 \mathrm{ng} / \mathrm{mL}$ for cortisol, and 1.0 and $2.5 \mathrm{ng} / \mathrm{mL}$ for cortisone, respectively. The average cortisol concentration $(133.9 \pm 63.7 \mathrm{ng} / \mathrm{mL})$ of samples collected between 9:00 and 11:00 a.m. was higher approximately 4.4 times than that of cortisone $(30.5 \pm 10.7 \mathrm{ng} / \mathrm{mL})(P<0.0001)$. The average cortisone/cortisol ratio was 0.225 . Therefore, the LCMS/MS method may be useful for the diagnosis of some adrenal diseases and the assessment of $11 \beta$-hydroxysteroid dehydrogenase $(11 \beta$-HSD) activity in clinical laboratories.

\section{Introduction}

Glucocorticoids are a class of steroid hormones that bind to the glucocorticoid receptor and contribute to the hypothalamic-adrenal-pituitary feedback system. They are part of the feedback mechanism in the immune system that turns immune activity down and therefore used to treat diseases caused by an overactive immune system, such as sepsis [1], allergies [2], autoimmune diseases, and asthma [3].

$11 \beta$-Hydroxysteroid dehydrogenase (11 $\beta$-HSD) is an enzyme that catalyzes the interconversion of physiologically active $11 \beta$-hydroxyl glucocorticoid, cortisol, and inactive 11keto glucocorticoid, cortisone. Endogenous cortisol is reversibly converted to cortisone by $11 \beta$-HSD type $1[4]$ whereas $11 \beta$-HSD type 2 predominantly catalyzes the conversion of cortisol to cortisone mostly in mineralocorticoid target tissues [5-8], and deficiency of this enzyme causes the syndrome of apparent mineralocorticoid excess (AME) $[9,10]$. Cortisol is the most important glucocorticoid showing clinical immunologic, cardiovascular, homeostatic, and some metabolic functions [11-13]. Although cortisone is a more prevalent steroid in fetal tissues than cortisol, the level of cortisone decreases immediately after birth [14].

Cortisol and cortisone are measured directly from biological samples using immunoassays including radioimmunoassay (RIA), enzyme-linked immunosorbent assay (ELISA), and chemiluminescent immunoassay (CLIA) [15]. Among them, CLIA has become the most extensive method due to advantages such as automation, high throughput, and ease of use. However, it suffers from serious disadvantages such 
as sample matrix effects and lack of specificity resulting from cross-reactivity with structurally related endogenous steroids, lipids, or metabolites [16-18]. Therefore, a highly sensitive and specific analytical tool is needed to determine the concentrations of the two very similar molecules such as cortisol and cortisone in serum. In this respect, LCMS/MS is becoming one of the most specific techniques available in clinical laboratories. LC-MS/MS also provides a robust platform with sufficient sensitivity and specificity for measuring steroid hormones simultaneously $[17,19]$.

Reference values of cortisol or cortisone vary between clinical laboratories due to the use of different analytical methods or in-house methods. Thus, validated assays are needed to measure glucocorticoid hormones accurately in samples originated from human. Although the levels of cortisol and cortisone in serum collected from healthy Japanese subjects between 9:00 and 11:00 a.m. were reported using high-performance liquid chromatography (HPLC) method [20], no study reported those in serum from Korean adults at the same time using LC-MS/MS method. At present, almost every clinical laboratory in Korea uses immunoassay-based methods to measure cortisol or cortisone in blood.

In this study, the assay method was validated following the recommendations outlined by the Food and Drug Administration (FDA) of the United States [21]. Evaluation of the method's performance included linearity, sensitivity, precision, accuracy, recovery, and interference. The aim of this study is to evaluate the $11 \beta$-HSD activity by measuring the concentrations of the two steroids in serum collected from Korean healthy volunteers between 9:00 and 11:00 a.m.

\section{Material and Methods}

2.1. Materials. Standards of cortisol (98\%) and cortisone (98\%) were purchased from Sigma Chemical Co. (St. Louis, MO, USA). Deuterated cortisol (cortisol-9, 11, 12, 12- $d_{4}, 98 \%$ ) as an internal standard (IS) was purchased from Cambridge Isotope Laboratories, Inc. (MA, USA). Analytical-grade ammonium acetate $(\geq 98 \%)$ and ethyl acetate $(99.8 \%)$ and activated charcoal were purchased from Sigma. Gibco fetal bovine serum (FBS) was purchased from Life Technologies (CA, USA). HPLC-grade methanol and water were purchased from Fisher Scientific Korea Ltd. (Seoul, Republic of Korea). All solvents were filtered through Advantec membranes with $0.45 \mu \mathrm{m}$ pore size (Toyo Roshi Kaisha, Ltd., Tokyo, Japan).

2.2. Sample Collection. Forty-eight healthy adult volunteers (male $=6$, female $=42$, average age $=38$ ) who had not received any hormone supplementation were recruited. All serum samples were collected at 9:00-11:00 a.m. using SST tubes (BD Inc., NJ, USA) and stored at $-70^{\circ} \mathrm{C}$ until assay. Although most of the samples were collected from women, all the samples were studied as recruited, due to no meaningful difference between male and female in the concentrations of cortisol and cortisone [22]. Informed consent was obtained from all study participants, and the study protocols were approved by the Institutional Review Board of Seoul Medical Science Institute.
2.3. Standards and Sample Preparation. Stock solutions of cortisol, cortisone, and cortisol- $d_{4}$ were prepared in methanol at a concentration of $100 \mu \mathrm{g} / \mathrm{mL}$. Working standards were prepared from the stock standards at a concentration of $1 \mu \mathrm{g} / \mathrm{mL}$. IS was prepared at a concentration of $0.1 \mathrm{mg} / \mathrm{mL}$ in methanol. Finally, the calibration standards were prepared in charcoal-stripped 5\% FBS at concentrations of $1.0,5.0,10.0,50.0,100.0$, and $500.0 \mathrm{ng} / \mathrm{mL}$ for cortisol and $2.5,5.0,10.0,25.0,50.0$, and $100.0 \mathrm{ng} / \mathrm{mL}$ for cortisone. All the standards were stored at $-20^{\circ} \mathrm{C}$ until assay. Sample preparation was a modification of two published procedures [23, 24]. Briefly, an aliquot of serum $(100 \mu \mathrm{L})$ was transferred into a glass tube and mixed with $20 \mu \mathrm{L}$ of working IS. For extraction, $2 \mathrm{~mL}$ of ethyl acetate was added into the tube. The tube was vortexed gently on a vortex mixer for $30 \mathrm{~s}$ and centrifuged at 3,000 rpm for $5 \mathrm{~min}$. The upper layer was removed and then the lower organic layer was evaporated to dryness under nitrogen gas. No solid-phase extraction was done. The dried extract was reconstituted with $300 \mu \mathrm{L}$ of methanol, which was transferred to screw-capped injection vial.

2.4. LC-MS/MS Characteristics. HPLC was performed using an Agilent 1200 series (Palo Alto, CA, USA) equipped with an autoinjector and an autosampler. Separations of the steroids were performed on a Capcell Pak MG-II C18 column (3.0 mm, i.d., $\times 50 \mathrm{~mm}$, l. $3 \mu \mathrm{m}$ particle size) (Shiseido, Tokyo, Japan). The injection volume was $5 \mu \mathrm{L}$ and the oven temperature was $25^{\circ} \mathrm{C}$. The mobile phase consisted of $5 \mathrm{mM}$ ammonium acetate and methanol $(25: 75, \mathrm{v} / \mathrm{v})$ and was delivered at a flow rate of $0.25 \mathrm{~mL} / \mathrm{min}$. Mass spectral detection of positive ions in multiple-reaction monitoring (MRM) mode was performed using an API 4000 triple-quadrupole mass spectrometer (Applied Biosystems/MDS SCIEX, CA, USA) equipped with a Turbo $\mathrm{V}$ source and a TurbolonSpray probe. The following $\mathrm{m} / \mathrm{z}$ MRM transitions were selected: $363.2 \rightarrow$ 121.2 for cortisol, $361.2 \rightarrow 163.2$ for cortisone, and $367.1 \rightarrow$ 121.1 for cortisol- $d_{4}$. The declustering potential (DP), entrance potential (EP), collision energy (CE), and collision cell exit potential (CXP) were optimized at $79 \mathrm{~V}, 10 \mathrm{~V}, 33 \mathrm{~V}$, and $6 \mathrm{~V}$ for cortisol, $111 \mathrm{~V}, 10 \mathrm{~V}, 33 \mathrm{~V}$, and $30 \mathrm{~V}$ for cortisone, and $79 \mathrm{~V}, 10 \mathrm{~V}$, $33 \mathrm{~V}$, and $6 \mathrm{~V}$ for cortisol- $d_{4}$, respectively. Ionspray voltage (IS) and temperature were $5500 \mathrm{~V}$ and $500^{\circ} \mathrm{C}$, respectively. Collision gas (CAD), curtain gas (CUR), and ion source gases 1 (GS1) and 2 (GS2) were 6, 20, 60, and 45 psi, respectively. Peak areas of each analyte and the corresponding IS were obtained using Analyst 1.5 data processing software (Applied Biosystems/MDS SCIEX, CA, USA).

2.5. Method Validation. For the validation of the method's performance, linearity, LOD, LOQ, accuracy, precision, recovery, and interference were evaluated. Method validation was performed following the guideline outlined by the FDA [21].

2.5.1. Linearity and Sensitivity. The linearity was evaluated by analyzing the regression coefficients of extracted cortisol and cortisone standard at 1.0, 5.0, 10.0, 50.0, 100.0, and $500.0 \mathrm{ng} / \mathrm{mL}$ and at 2.5, 5.0, 10.0, 20.0, 50.0, and $100 \mathrm{ng} / \mathrm{mL}$, 
respectively. Each standard was analyzed in five different runs on five days. Serial dilution of a $5.0 \mathrm{ng} / \mathrm{mL}$ sample of cortisol and cortisone using charcoal-stripped 5\% FBS was used to prepare the lowest concentration and to evaluate the LOD and LOQ. These samples were analyzed in ten replicates per run. The LOD and LOQ were determined as the lowest concentrations at which the analyte peaks were present at the expected retention times and the signal-to-noise $(\mathrm{S} / \mathrm{N})$ ratios $>3$ and $>10$, respectively. The limit of quantitation (LOQ) was determined as the lowest concentration for which accuracy was within $\pm 20 \%$ and imprecision was within $\pm 15 \%$.

2.5.2. Accuracy and Precision. Accuracy and precision are defined as the closeness between the concentrations of the analytes in a standard solution or in a spiked sample and the true concentrations and as the reproducibility of the signals observed by different analysis of an aliquot containing the analytes using a standard solution or spiked sample, respectively [25]. The accuracy and precision were determined from QC samples at four different concentrations of the two steroids (1.0, 5.0, 50.0, and $500.0 \mathrm{ng} / \mathrm{mL}$ for cortisol and 2.5, 5.0, 25.0, and $100.0 \mathrm{ng} / \mathrm{mL}$ for cortisone) including the LOQ concentrations. The QC samples were prepared from charcoal-stripped 5\% FBS spiked with the four different amounts of cortisol and cortisone using stock solutions that were independent of those used to prepare the calibrators. The intra-assay accuracy and precision were evaluated by analyzing the three QC samples 5 times on 1 day. The interassay accuracy and precision were evaluated by analyzing the samples over five different days.

2.5.3. Recovery. Recovery is defined as the closeness between the concentration observed by applying the present assay method to a spiked sample and the true concentration spiked to the sample matrix [25]. Recovery was evaluated using serum samples with low concentrations of the two steroids, spiked with the analyte standards at 5.0, 50.0, and $500.0 \mathrm{ng} / \mathrm{mL}$ for cortisol and 5.0, 25.0, and $100.0 \mathrm{ng} / \mathrm{mL}$ for cortisone.

2.5.4. Interference. Interference studies were performed by spiking a pooled serum with $10 \mathrm{ng} / \mathrm{mL}$ of the following compounds: corticosterone, 11-deoxycortisol, progesterone, testosterone, 17-hydroxyprogesterone, dihydrotestosterone, aldosterone, and dehydroepiandrosterone. Interfering peaks at the cortisol and cortisone channels were identified.

2.6. Statistical Analysis. Data processing and graphic presentation were carried out with MS Office Excel 2007 (Microsoft Inc., Seattle, WA, USA). The concentrations of serum cortisol and cortisone were assessed statistically using the Student t-test. Statistical analysis was performed using GraphPad software (QuickCalcs, La Jolla, CA, USA). $P<0.05$ was considered statistically significant.

\section{Results and Discussion}

3.1. LC-MS/MS Analysis. It is needed to confirm that there are no interferences near the retention times of the analytes from a matrix as complex as serum $[26,27]$. Therefore, the blank, the blank spiked with the standards $(10 \mathrm{ng} / \mathrm{mL}$ for cortisol and $10 \mathrm{ng} / \mathrm{mL}$ for cortisone), and a serum sample from a healthy subject were analyzed. No peaks were observed in the blank sample (Figure 1(a)). In the MRM chromatogram of the blank spiked with the standards, cortisol, cortisone, and IS were fully separated within $3 \mathrm{~min}$ (Figure 1(b)). The retention times in the MRM chromatogram were $1.9 \mathrm{~min}$ for cortisol, $1.75 \mathrm{~min}$ for cortisone, and $1.91 \mathrm{~min}$ for cortisol- $d_{4}$. The MRM chromatogram of a serum sample from a healthy subject showed that physiological components in the serum did not interfere with the identification and quantification of the analytes (Figure 1(c)). These results also indicate that the rapid analytical time and relatively small sample volume should facilitate high throughput measurement of both cortisol and cortisone simultaneously in human serum.

3.2. Method Performance. A simultaneous quantitative assay method for cortisol and cortisone in serum was validated. The calibration curves were linear in the range of $1.0-500.0 \mathrm{ng} / \mathrm{mL}$ for cortisol $(y=(0.03431 \pm 0.00471) x+0.00783)$ and $2.5-$ $100.0 \mathrm{ng} / \mathrm{mL}$ for cortisone $(y=(0.02539 \pm 0.00099) x-$ $0.00784)$. The weighed $(1 / X)$ least-squares determination coefficients were greater than 0.999 for cortisol and 0.998 for cortisone, indicating very good linearity.

The LOQ was found to be $1.0 \mathrm{ng} / \mathrm{mL}(2.75 \mathrm{nmol} / \mathrm{L})$ for cortisol and $2.5 \mathrm{ng} / \mathrm{mL}(6.87 \mathrm{nmol} / \mathrm{L})$ for cortisone (Table 1), indicating the values were within a biologically relevant range [23]. No ion suppression was observed at the retention times of the analytes.

The precisions (\% coefficient of variations, CVs) and the accuracies of the LC-MS/MS method were determined by analyzing QC samples at four different concentrations for cortisol and cortisone (Table 1$)$. Intra-assay $(n=5) \mathrm{CVs}$ ranged from 2.7 to 4.6 for cortisol and 3.6 to 6.0 for cortisone, while accuracies (\% bias) ranged from 95.4 to 102.5 for cortisol and 92.0 to 98.8 for cortisone. Interassay $(n=5) \mathrm{CVs}$ ranged from 1.5 to 4.5 for cortisol and 1.9 to 5.8 for cortisone, while accuracies ranged from 97.3 to 100.4 for cortisol and 89.2 to 96.0 for cortisone. These results indicate that the $\mathrm{CVs}$ and the accuracies were within internationally accepted criteria [21]. The recoveries of cortisol were 99.0, 96.1, and 94.0\% in serum samples spiked with the standards at 5.0, 50.0, and $500.0 \mathrm{ng} / \mathrm{mL}$, respectively. The recoveries of cortisone were also $77.1,81.6$, and $81.2 \%$ in serum samples spiked with the standards at 5.0, 25.0, and $100.0 \mathrm{ng} / \mathrm{mL}$, respectively (Table 1).

3.3. Quantitative Analysis of Sera from Subjects. The mean concentration of cortisol $(133.9 \pm 63.7 \mathrm{ng} / \mathrm{mL})$ was about 4.4 times higher than that of cortisone $(30.5 \pm 10.7 \mathrm{ng} / \mathrm{mL})$ at 9:00-11:00 a.m. $(P<0.0001)$ (Table 2$)$. The mean concentrations of cortisol and cortisone were 132.9 and $27.8 \mathrm{ng} / \mathrm{mL}$ for male and 134.0 and $31.0 \mathrm{ng} / \mathrm{mL}$ for female, respectively. These results are similar to the established reference intervals for cortisol and cortisone in healthy American subjects by LC-MS/MS assay $[23,24]$ or in healthy Japanese subjects by HPLC assay $[20,28]$. In our study, no significant differences between male and female's cortisol or cortisone levels were 


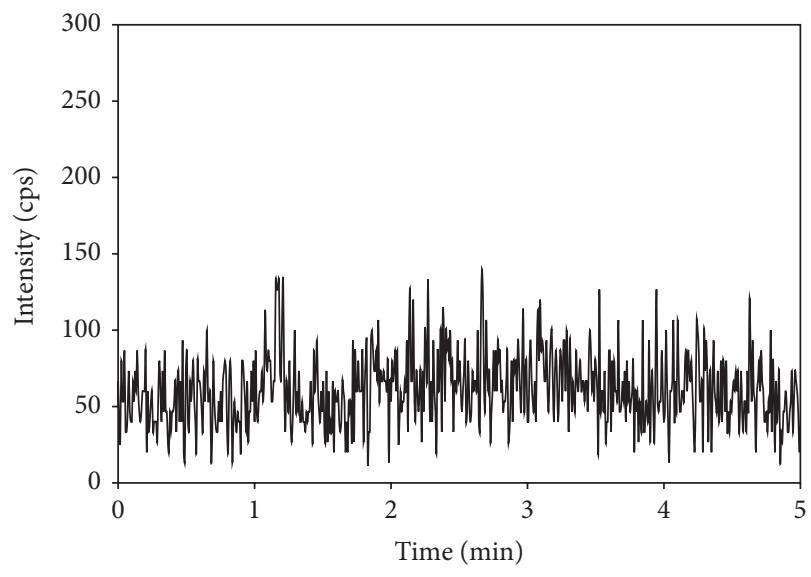

(a)

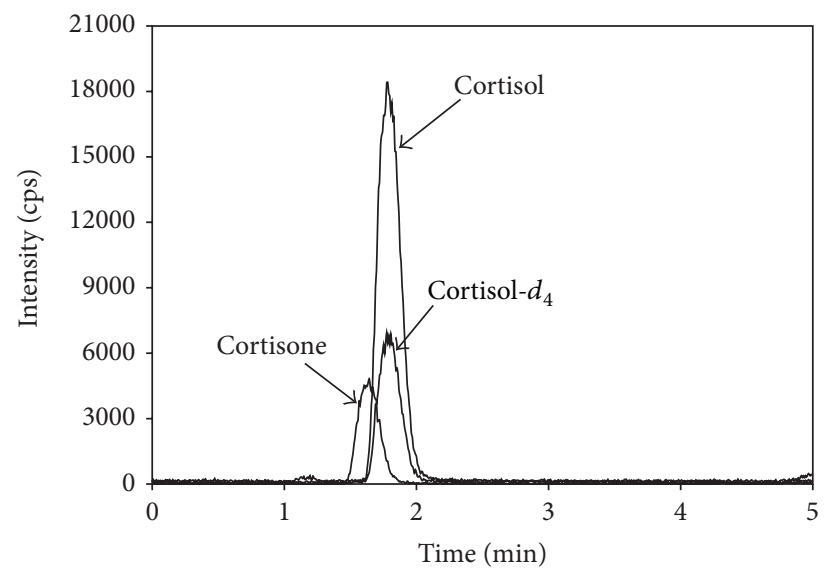

(b)

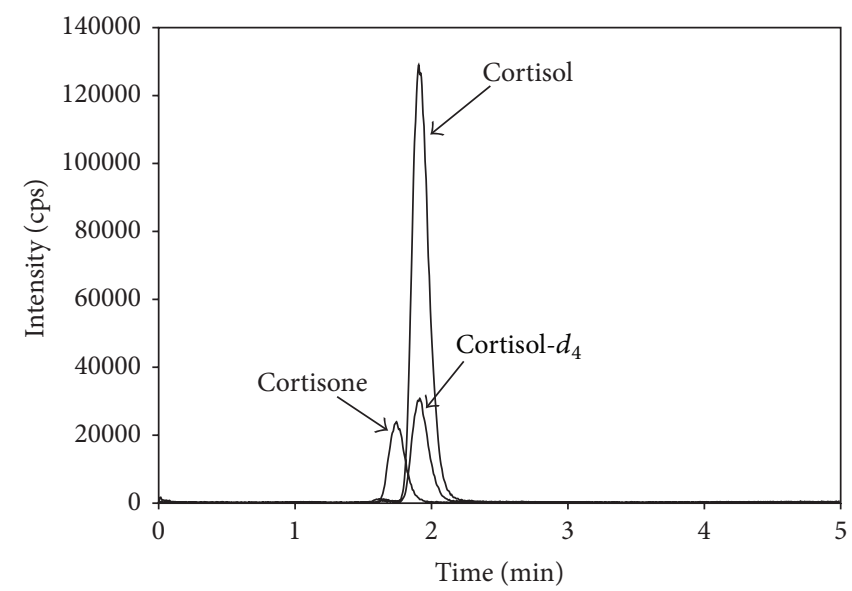

(c)

FIGURE 1: MRM chromatograms obtained by the present assay method. (a) Charcoal-stripped 5\% FBS (blank). (b) A blank sample spiked with the standards at the concentrations of $10 \mathrm{ng} / \mathrm{mL}$ of cortisol and $10 \mathrm{ng} / \mathrm{mL}$ of cortisone and with $20 \mu \mathrm{L}$ of working IS. (c) A healthy subject serum with the concentrations of $25 \mathrm{ng} / \mathrm{mL}$ of cortisol and $50 \mathrm{ng} / \mathrm{mL}$ of cortisone.

TABLE 1: Method validation results of the LC-MS/MS assay.

\begin{tabular}{|c|c|c|c|c|c|c|c|}
\hline & \multirow{2}{*}{ Concentration $(\mathrm{ng} / \mathrm{mL})$} & \multicolumn{2}{|c|}{ Intra-assay $(n=5)$} & \multicolumn{2}{|c|}{ Interassay $(n=5)$} & \multirow{2}{*}{ Recovery (\%) } & \multirow{2}{*}{ LOQ (ng/mL) } \\
\hline & & Accuracy (\%) & $\mathrm{CV}(\%)$ & Accuracy (\%) & CV (\%) & & \\
\hline \multirow{4}{*}{ Cortisol } & 1.0 & 95.4 & 4.6 & 97.3 & 4.5 & & \multirow{4}{*}{1.0} \\
\hline & 5.0 & 99.2 & 2.9 & 100.4 & 2.1 & 99.0 & \\
\hline & 50.0 & 102.5 & 5.3 & 100.4 & 1.6 & 96.1 & \\
\hline & 500.0 & 96.4 & 2.7 & 97.3 & 1.5 & 94.0 & \\
\hline \multirow{4}{*}{ Cortisone } & 2.5 & 98.8 & 6.0 & 92.8 & 5.8 & & \multirow{4}{*}{2.5} \\
\hline & 5.0 & 94.0 & 4.5 & 90.1 & 2.9 & 77.1 & \\
\hline & 25.0 & 92.0 & 5.6 & 89.2 & 1.9 & 81.6 & \\
\hline & 100.0 & 97.3 & 3.6 & 96.0 & 2.3 & 81.2 & \\
\hline
\end{tabular}

TABLE 2: Mean concentrations (ng/mL) of cortisol and cortisone in serum collected between 9:00 and 11:00 a.m.

\begin{tabular}{|c|c|c|c|c|c|}
\hline & Mean age & Cortisol (range) & Cortisone (range) & Cortisone/cortisol ratios & $P$ value \\
\hline Male $(n=6)$ & 52.3 & $132.9(93.4-162.0)$ & $27.8(18.3-35.8)$ & 0.209 & \\
\hline Female $(n=43)$ & 35.2 & $134.0(46.1-267.0)$ & $31.0(14.1-55.7)$ & 0.231 & \\
\hline Total $(n=49)$ & 37.3 & 133.9 & 30.5 & 0.225 & $P<0.0001$ \\
\hline
\end{tabular}




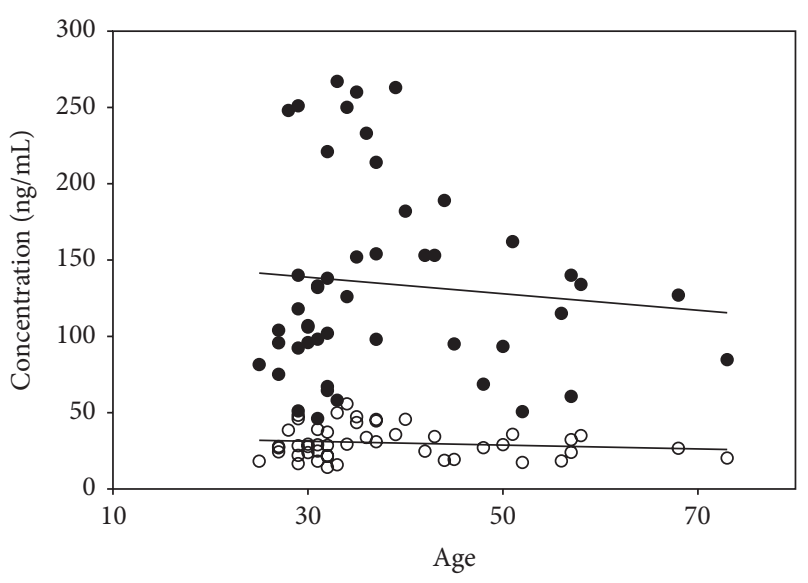

Figure 2: The levels of serum cortisol $(\bullet)$ and cortisone $(O)$ with age in subjects.

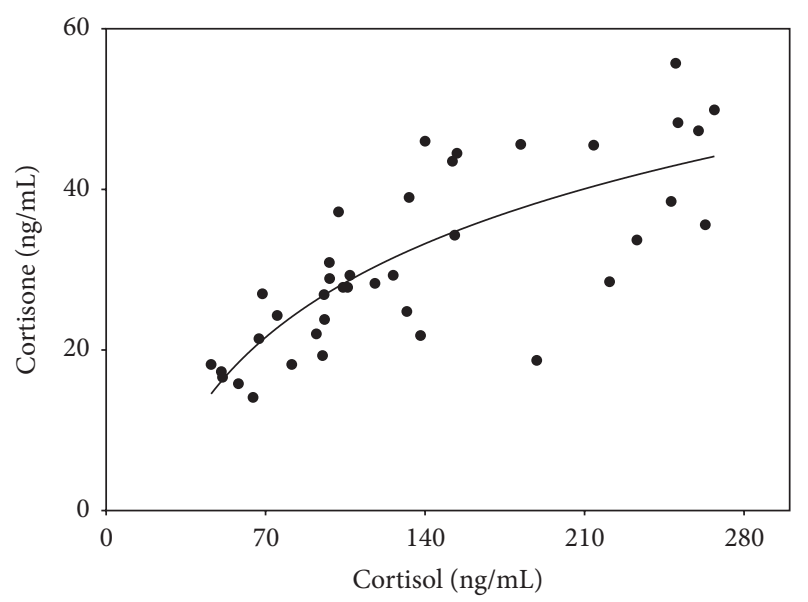

FIGURE 3: Comparison of the concentration levels between serum cortisol and cortisone collected between 9:00 and 11:00 a.m.

found, indicating that the levels of cortisol or cortisone in serum are regardless of gender [22].

Furthermore, the concentrations of cortisol and cortisone were not notably changed with increasing age (Figure 2). In a previous report, although healthy Japanese adults had higher levels of cortisol and cortisone than healthy children from 1 to 19 years old, the difference was not statistically notable [28].

The concentrations of serum cortisol were compared with those of serum cortisone (Figure 3). The fitted curve showed a tendency towards a plateau at higher concentration levels, which might indicate the saturation of the $11 \beta$-HSD type 2 at high concentrations of the substrate [29]. This result shows a status of cortisol-cortisone shuttle in serum and also gives an evidence for the activity of $11 \beta$-HSD type 2 that catalyzes the irreversible conversion of active cortisol into inactive cortisone [30].

No significant differences were found between males and females in the cortisone/cortisol ratios. The average ratio of males and females in this study was 0.225 (Table 2). This result showed similar pattern to the ratios previously measured in sera from 69 healthy Japanese subjects [20]. It is well known that the cortisone/cortisol ratio is decreased in hyperadrenalism and under physiological stress but is increased in hypoadrenalism. Therefore, the cortisone/cortisol ratio can give useful information in evaluating the adrenal function of patients with various diseases $[20,22,24,28]$.

\section{Conclusions}

In this study, the levels of cortisol and cortisone in the sera from healthy Korean subjects were simultaneously measured using a validated LC-MS/MS method after a simple liquidliquid extraction. To the best of our knowledge, this work is the first report on simultaneous measurement of cortisol and cortisone in the sera from healthy Korean subjects by LCMS/MS. The present LC-MS/MS method is rapid, sensitive, specific, and robust for the simultaneous measurements of cortisol and cortisone in serum. The method also may be cost-effective compared with the previous reports using any solid-phase extraction cartridge [31] or online extraction equipment [32]. The level of serum cortisone was lower about 4 times than that of cortisol and the average cortisone/cortisol ratio was 0.225 . Also, the method may provide valuable information about $11 \beta-\mathrm{HSD}$ activity in the study of cortisolcortisone shuttle. Therefore, the LC-MS/MS method could be an alternative method to conventional enzyme immunoassays for the diagnosis of several adrenal dysfunctions in routine clinical laboratories.

\section{Conflict of Interests}

The authors declare that they have no conflict of interests.

\section{Authors' Contribution}

Sanghoo Lee and Hwan-Sub Lim contributed equally to this work and are considered co-first authors.

\section{Acknowledgments}

This work was supported by Seoul Medical Science Institute \& Seoul Clinical Laboratories in 2012.

\section{References}

[1] M. den Brinker, K. F. M. Joosten, O. Liem et al., "Adrenal insufficiency in meningococcal sepsis: bioavailable cortisol levels and impact of interleukin-6 levels and intubation with etomidate on adrenal function and mortality," Journal of Clinical Endocrinology and Metabolism, vol. 90, no. 9, pp. 5110-5117, 2005.

[2] A. Buske-Kirschbaum, "Cortisol responses to stress in allergic children: interaction with the immune response," NeuroImmunoModulation, vol. 16, no. 5, pp. 325-332, 2009.

[3] R. J. Scarfone and E. Friedlaender, "Corticosteroids in acute asthma: past, present, and future," Pediatric Emergency Care, vol. 19, no. 5, pp. 355-361, 2003.

[4] B. R. Walker, J. C. Campbell, R. Fraser, P. M. Stewart, and C. R. W. Edwards, "Mineralocorticoid excess and inhibition of $11 \beta$ hydroxysteroid dehydrogenase in patients with ectopic ACTH 
syndrome," Clinical Endocrinology, vol. 37, no. 6, pp. 483-492, 1992.

[5] A. K. Agarwal, T. Mune, C. Monder, and P. C. White, " $\mathrm{NAD}^{+}$-dependent isoform of $11 \beta$-hydroxysteroid dehydrogenase. Cloning and characterization of cDNA from sheep kidney," The Journal of Biological Chemistry, vol. 269, no. 42, pp. 25959-25962, 1994.

[6] G. Mazzocchi, G. P. Rossi, G. Neri, L. K. Malendowicz, G. Albertin, and G. G. Nussdorfer, " $11 \beta$-Hydroxysteroid dehydrogenase expression and activity in the human adrenal cortex," FASEB Journal, vol. 12, no. 14, pp. 1533-1539, 1998.

[7] B. L. Roland and J. W. Funder, "Localization of $11 \beta$-hydroxysteroid dehydrogenase type 2 in rat tissues: in situ studies," Endocrinology, vol. 137, no. 3, pp. 1123-1128, 1996.

[8] P. M. Stewart, C. B. Whorwood, and J. I. Mason, “Type $211 \beta$ hydroxysteroid dehydrogenase in foetal and adult life," Journal of Steroid Biochemistry and Molecular Biology, vol. 55, no. 5-6, pp. 465-471, 1995.

[9] C. R. Edwards, P. M. Stewart, D. Burt et al., "Localisation of $11 \beta$-hydroxysteroid dehydrogenase-tissue specific protector of the mineralocorticoid receptor," The Lancet, vol. 2, no. 8618, pp. 986-989, 1988.

[10] P. M. Stewart, J. E. T. Corrie, C. H. L. Shackleton, and C. R. W. Edwards, "Syndrome of apparent mineralocorticoid excess. A defect in the cortisol-cortisone shuttle," Journal of Clinical Investigation, vol. 82, no. 1, pp. 340-349, 1988.

[11] J. Krøll, "Correlations of plasma cortisol levels, chaperone expression and mammalian longevity: a review of published data," Biogerontology, vol. 11, no. 4, pp. 495-499, 2010.

[12] R. M. Reynolds, M. W. J. Strachan, J. Labad et al., "Morning cortisol levels and cognitive abilities in people with type 2 diabetes: the Edinburgh type 2 diabetes study," Diabetes Care, vol. 33, no. 4, pp. 714-720, 2010.

[13] P. Ferrari, "The role of $11 \beta$-hydroxysteroid dehydrogenase type 2 in human hypertension," Biochimica et Biophysica Acta, vol. 1802, no. 12, pp. 1178-1187, 2010.

[14] B. E. P. Murphy, "Ontogeny of cortisol-cortisone interconversion in human tissues: a role for cortisone in human fetal development," Journal of Steroid Biochemistry, vol. 14, no. 9, pp. 811-817, 1981.

[15] G. Holder, "Measurement of glucocorticoids in biological fluids," Methods in Molecular Biology, vol. 324, pp. 141-157, 2006.

[16] M. Rauh, "Steroid measurement with LC-MS/MS in pediatric endocrinology," Molecular and Cellular Endocrinology, vol. 301, no. 1-2, pp. 272-281, 2009.

[17] M. M. Kushnir, A. L. Rockwood, W. L. Roberts, B. Yue, J. Bergquist, and A. W. Meikle, "Liquid chromatography tandem mass spectrometry for analysis of steroids in clinical laboratories," Clinical Biochemistry, vol. 44, no. 1, pp. 77-88, 2011.

[18] B. E. P. Murphy, "How much "UFC" is really cortisol?" Clinical Chemistry, vol. 46, no. 6, pp. 793-794, 2000.

[19] C. J. Broccardo, K. L. Schauer, W. M. Kohrt, R. S. Schwarts, J. P. Murphy, and J. E. Prenni, "Multiplexed analysis of steroid hormones in human serum using novel microflow tile technology and LC-MS/MS," Journal of Chromatography B, vol. 934, no. 1, pp. 16-21, 2013.

[20] M. Homma, A. Tanaka, K. Hino et al., "Assessing systemic 11 $\beta$ hydroxysteroid dehydrogenase with serum cortisone/cortisol ratios in healthy subjects and patients with diabetes mellitus and chronic renal failure," Metabolism, vol. 50, no. 7, pp. 801-804, 2001.
[21] Guidance for Industry on Bioanalytical Method Validation, US Food and Drug Administration, Center for Drug Evaluation and Research, Department of Health and Services, Rockvill, Md, USA, 2001.

[22] S. Nomura, M. Fujitaka, N. Sakura, and K. Ueda, "Adrenocortical function in asthmatic children: low levels of adrenocortical hormones in children with persistent attacks," European Journal of Pediatrics, vol. 156, no. 4, pp. 323-328, 1997.

[23] M. M. Kushnir, R. Neilson, W. L. Roberts, and A. L. Rockwood, "Cortisol and cortisone analysis in serum and plasma by atmospheric pressure photoionization tandem mass spectrometry," Clinical Biochemistry, vol. 37, no. 5, pp. 357-362, 2004.

[24] P. C. Kao, D. A. Machacek, M. J. Magera, J. M. Lacey, and P. Rinaldo, "Diagnosis of adrenal cortical dysfunction by liquid chromatography-tandem mass spectrometry," Annals of Clinical and Laboratory Science, vol. 31, no. 2, pp. 199-204, 2001.

[25] J. Peris-Vincente, S. Carda-Broch, J. Esteve-Romero et al., "Validation of micellar LC-based methods applied to analyze foodstuffs," Bioanalysis, vol. 5, no. 4, pp. 481-494, 2013.

[26] J. Esteve-Romero, E. Ochoa-Aranda, D. Bose, M. RamblaAlegre, J. Peris-Vicente, and A. Martinavarro-Domínguez, "Tamoxifen monitoring studies in breast cancer patients by micellar liquid chromatography," Analytical and Bioanalytical Chemistry, vol. 397, no. 4, pp. 1557-1561, 2010.

[27] E. O. Aranda, J. Esteve-Romero, M. Rambla-Alegre, J. PerisVicente, and D. Bose, "Development of a methodology to quantify tamoxifen and endoxifen in breast cancer patients by micellar liquid chromatography and validation according to the ICH guidelines," Talanta, vol. 84, no. 2, pp. 314-318, 2011.

[28] S. Nomura, M. Fujitaka, K. Jinno, N. Sakura, and K. Ueda, "Clinical significance of cortisone and cortisone/cortisol ratio in evaluating children with adrenal diseases," Clinica Chimica Acta, vol. 256, no. 1, pp. 1-11, 1996.

[29] S. H. van Uum, J. W. Lenders, and A. R. Hermus, "Cortisol, 11 $\beta$ hydroxysteroid dehydrogenases, and hypertension," Seminars in Vascular Medicine, vol. 4, no. 2, pp. 121-128, 2004.

[30] G. Morineau, A. Boudi, A. Barka et al., "Radioimmunoassay of cortisone in serum, urine, and saliva to, assess the status of the cortisol-cortisone shuttle," Clinical Chemistry, vol. 43, no. 8, pp. 1397-1407, 1997.

[31] J. A. Ray, M. M. Kushnir, A. L. Rockwood, and A. W. Meikle, "Analysis of cortisol, cortisone and dexamethasone in human serum using liquid chromatography tandem mass spectrometry and assessment of cortisol: cortisone ratios in patients with impaired kidney function," Clinica Chimica Acta, vol. 412, no. 13-14, pp. 1221-1228, 2011.

[32] M. Vogeser, R. Zachoval, and K. Jacob, "Serum cortisol/cortisone ratio after Synacthen stimulation," Clinical Biochemistry, vol. 34, no. 5, pp. 421-425, 2001. 

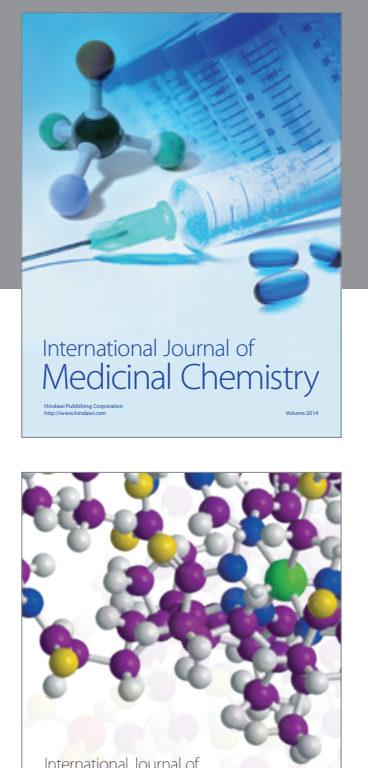

\section{Carbohydrate} Chemistry

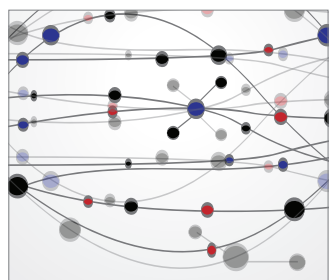

The Scientific World Journal
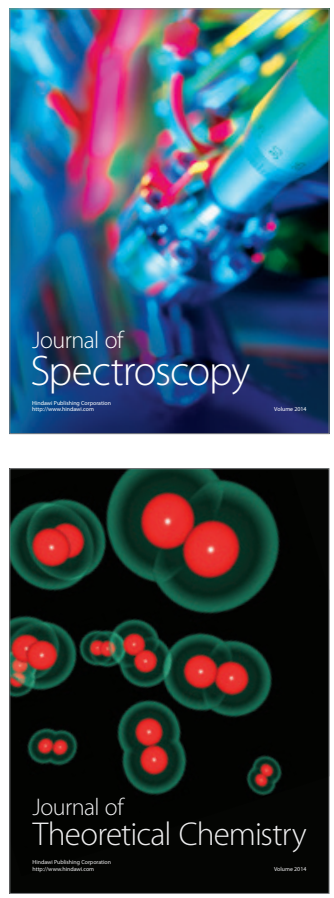
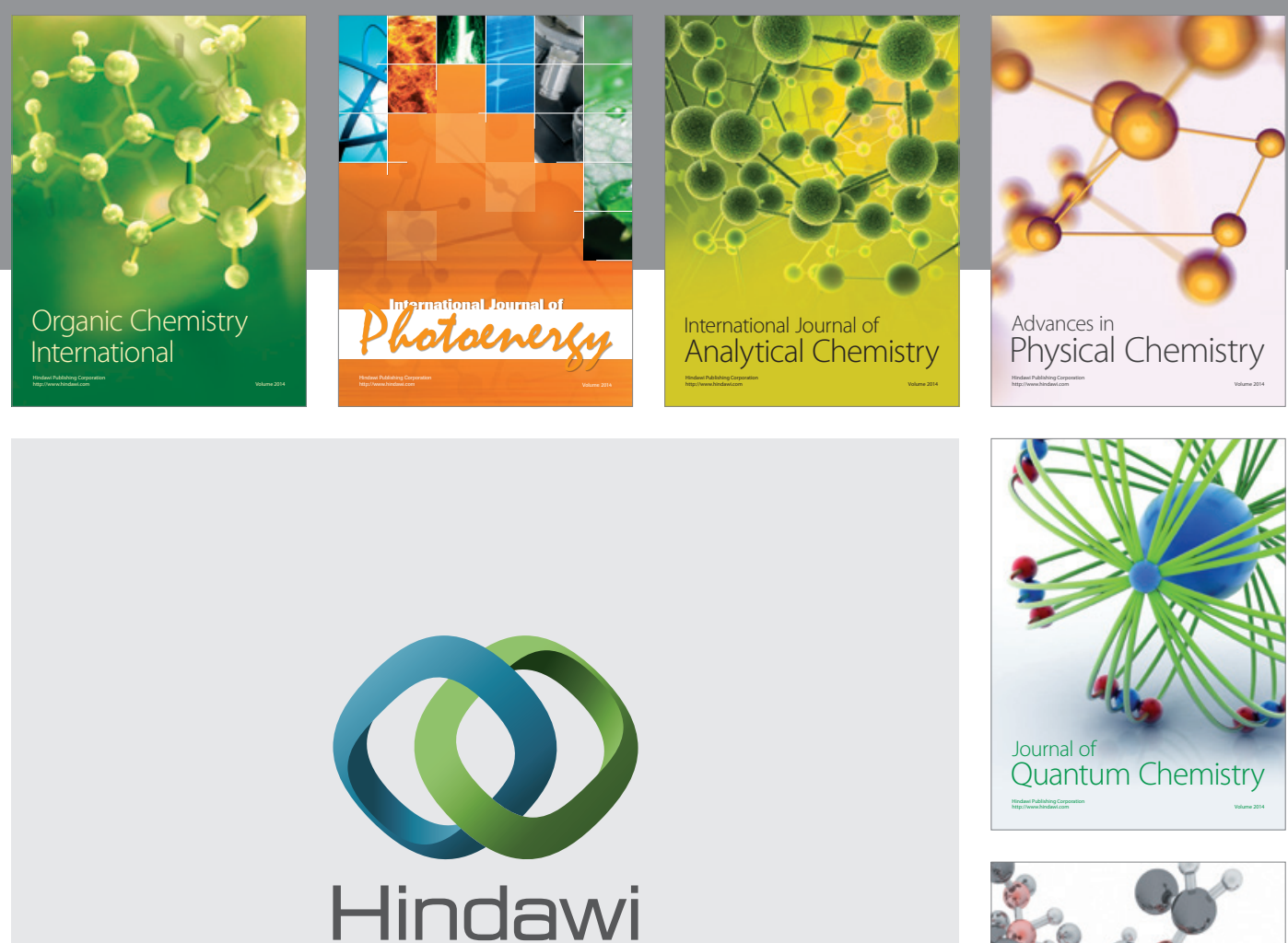

Submit your manuscripts at

http://www.hindawi.com

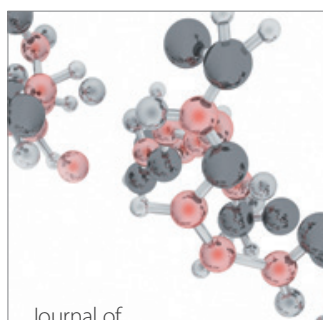

Analytical Methods

in Chemistry

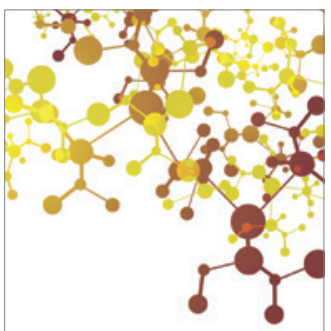

Journal of

Applied Chemistry

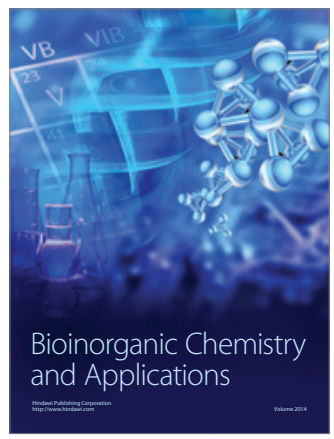

Inorganic Chemistry
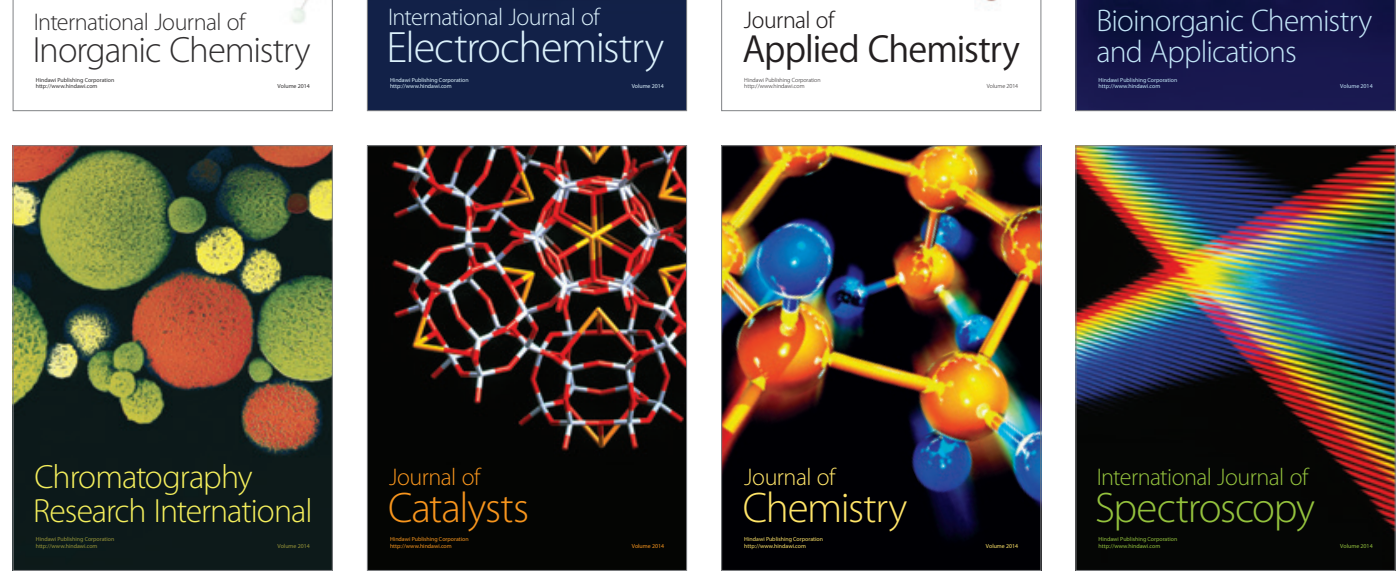